\title{
PERANCANGAN ENTERPRISE ARCHITECTURE MENGGUNAKAN ZACHMAN FRAMEWORK PADA PERUSAHAAN JEWELRY
}

\section{THE DESIGNING OF ENTERPRISE ARCHITECTURE USING ZACHMAN FRAMEWORK AT JEWELRY COMPANY}

\author{
Hendy Tannady ${ }^{1)^{*}}$, Titus Zefanya Ivgantius ${ }^{2)}$, Timothy Jason Andreas ${ }^{3)}$, Felix ${ }^{4)}$ \\ ${ }^{1)}$ Program Studi Magister Manajemen, Institut Teknologi dan Bisnis Kalbis, Jakarta \\ ${ }^{2,3,4)}$ Program Studi Sistem Informasi, Universitas Bunda Mulia, Jakarta
}

Diterima 15 Maret 2021 / Disetujui 22 Maret 2021

\begin{abstract}
Data mining is one form of implementation that is applied to look for models and patterns that can make predictions on data based on previous data at a certain time period. Suicide is one of the social problems that occur in various countries. RapidMiner is one of the well-known data mining tools and is used for data mining. With Rapidminer, we can compare datasets containing socio-economic information at a level that is appropriate to the year and country. Suicide is an act that is self-inflicted, an action that involves self-injury with non-fatal results and there is evidence, both confirmed and implicit of the desire to die. In this journal, we will process data from the Suicide Kaggle Review Level 1985 to 2016 in various countries using data mining techniques. The data collection method used in this research is literature study and the research method used is descriptive to analyze, create and overcome the problems needed. This research aims to study and solve models and patterns from data made by each country and is expected to make a positive contribution in relation to self defense and reduce numbers in each country. This journal provides the results of the analysis using a tool called RapidMiner to show models and patterns from the Kaggle Data Suicide Rate Review 1985 to 2016.
\end{abstract}

Keywords: Jewelry Company, Enterprise Achitecture Planning, Zachman Framework.

\begin{abstract}
ABSTRAK
Jewelry Company merupakan perusahaan yang memproduksi perhiasan dengan memberikan kualitas yang terbaik kepada konsumennya. Dalam perkembangannya, jewelry Company memiliki sebuah pabrik yang memproduksi berbagai jenis perhiasan diantaranya emas, perak, ruby, permata, topaz dan sapphire. Namun, dalam perencanaan SI/TI di dalam perusahaan tersebut masih terbilang kurang memaksimalkan penggunaan SI/TI yang seharusnya diterapkan di dalam sebuah perusahaan. Oleh sebab itu, perusahaan ini memerlukan sebuah perencanaan yang lebih strategis untuk mendukung tujuan bisnis yang selaras dengan strategi bisnis dan strategi SI/TI. Enterprise Architecture Planning dipilih sebagai panduan dan Zachman Framework sebagai metode dalam perancangan yang terdiri dari enam baris yaitu scope, enterprise model, system model, technology constrained model, retailed representations, dan functioning enterprise, serta enam kolom yang terdiri dari what, how, where, who, when, dan why. Hasil dari penelitian ini adalah sebuah usulan rancangan arsitektur yang disarankan kepada perusahaan diharapkan dapat mendukung penuh kegiatan bisnis yang berjalan agar lebih optimal dan efektif.
\end{abstract}

Kata Kunci: Perusahaan Jewelry, Perencanaan Enterprise Architecture, Zachman Framework.

\footnotetext{
*Korespondensi Penulis:

E-mail: hendytannady@kalbis.ac.id
} 


\section{PENDAHULUAN}

Jewelry Company adalah perusahaan perhiasan ritel terbesar di Asia Tenggara yang menyuguhkan macammacam perhiasan terbaik kepada pembelinya dan tersebar hampir di seluruh Indonesia, seperti di daerah Jakarta, Tanggerang dan Medan. Dalam hal ini perusahaan tersebut kini telah mengoperasikan penjualan perhiasan dengan memfokuskan ke berbagai jenis perhiasan dan permata agar dapat memberikan kepuasan kepada pelangganpelanggannya.

Untuk dapat mendukung proses bisnis yang dijalankan oleh Jewelry Company sebagai perusahaan yang memiliki keunggulan dalam persaingan dengan ritel-ritel perhiasan lainnya, maka perusahaan tersebut sebaiknya menerapkan SI/TI yang dapat membantu aktivitas proses bisnis di perusahaan tersebut sehingga dapat meningkat secara bertahap menuju peranan yang lebih strategis (Irmanyani, 2017) dan (Hizbullah dkk, 2015). Dalam hal ini SI/TI yang diterapkan haruslah memperhatikan suatu proses pembangunan sistem serta perencanaan yang matang dengan memperhatikan semua kepentingan setiap pihak yang terlibat dengan sistem tersebut, baik itu pihak managemen sebagai pihak yang bertanggung jawab terhadap kinerja organisasi, pihak pengembang yang bertanggung jawab terhadap sistem yang dibangun, maupun pengguna yang bertanggung jawab terhadap pemanfaatan sistem yang sedang dibangun (Saputra, 2015).

Oleh karena itu, dibutuhkan sebuah Enterprise Architecture Planning yang mampu mengakomodasi seluruh kepentingan setiap kebutuhan SI/TI yang diterapkan didalam suatu organisasi dibangun (Saputra, 2015). EA sendiri merupakan pendekatan modern untuk melakukan perencanaan terhadap kualitas data dan mencapai misi SI serta proses yang dilakukan untuk mendukung bisnis dan rencana implementasi pada bidang arsitektural dan startegis yang meliputi informasi, sistem bisnis dan arsitektur teknik (Subagio, 2012) dan (Bakar dkk, 2016). Dalam pelaksanaannya, metode EAP juga berhubungan langsung dengan framework-framework lain, salah satunya yaitu Zachman Framework.

Zachman Framework merupakan salah satu metode EA (Enterprise Enterprise) yang banyak digunakan diseluruh dunia dalam perancangan sistem dimana didalam metode ini perencanaan dilakukan dengan langkah-langkah yang sistematis, mudah dipahami, dan dapat dijadikan control untuk pengembangan sistem informasi ke depan (Slameto dkk, 2016).

Sehingga dari penjelasan tersebut, peneliti menyimpulkan untuk melakukan perencanaan dalam hal penerapan SI/TI dengan menggunakan metode EA yang disertakan dengan Zachman Framework. Dengan demikian, diharapkan agar penelitian ini dapat menghasilkan suatu rancangan yang baik terhadap sistem dan proses bisnis baru maupun aplikasi yang dapat berjalan selaras dengan tujuan dan pencapaian bisnis yang ada di perusahaan yang bersangkutan

\section{METODE PENELITIAN}

\section{A. Jenis Penelitian}

Penelitian ini dilakukan dengan menggunakan metode deskriptif karena pada saat melaksanakan penelitiannya berhubungan dengan data, analisis, dan interprestasi tentang arti atau deskripsi terhadap data yang diperoleh dari narasumber. 


\section{B. Metode Pengumpulan Data}

Pada kegiatan penelitian ini, penulis melakukan pengumpulan data dengan beberapa cara, yaitu:

a. Studi literatur, dalam menyusun laporan peneliti menggunakan bahanbahan yang berkaitan dengan penelitian ini yang berasal dari jurnal-jurnal ilmiah, prosiding, internet dan media publikasi lainnya yang layak dan sesuai untuk dijadikan sumber masukan bagi penelitian ini.

b. Wawancara, dalam penyusunan laporan, peneliti melakukan wawancara dengan pihak pekerja dari Jewelry Company yang memahami proses bisnis yang berjalan didalam perusahaan tersebut.

c. Observasi/Pengamatan, pengamatan dilakukan di Jewelry Company berpusat di Jakarta. Hal ini bertujuan untuk dapat menganalisis kebutuhan perancangan arsitektur sistem informasi di perusahaan tersebut.

\section{Tahapan Penelitian}

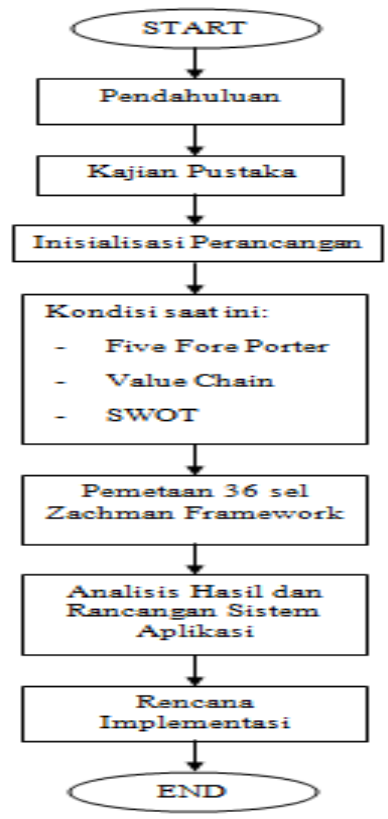

Gambar 1. Tahapan Penelitian (Kristanto, 2016).
Dalam penyusunan laporan terdapat tahapan penelitian yang dilakukan oleh peneliti pada gambar 1 .

\section{Zachman Framework}

\section{Zachman}

Framework

menggambarkan arsitektur organisasi secara umum dan menguraikannya ke dalam bentuk enterprise sistem yang kompleks. Kerangka kerja ini, kemudian, berisi rencana global serta rincian teknis, daftar dan grafik, yang dapat dipahami dengan mudah. Dengan merancang sistem sesuai dengan kerangka kerja ini, maka developer dapat merancang desain yang bersih, mudah dimengerti, seimbang, dan lengkap.

Kolom dari Zachman Framework mendefinisikan fokus yang berbedabeda atau menggambarkan abstraksi produk dari berbagai perspektif. Tiap fokus mengacu pada sebuah pertanyaan dimana cara pertanyaan itu dijawab sangat tergantung pada perspektif. Dengan kata lain, perspektif mengharuskan bentuk dan rincian yang diperlukan untuk membuat setiap pertanyaan menjadi jelas dan dimengerti (Pramana dan Yuningsih, 2013)

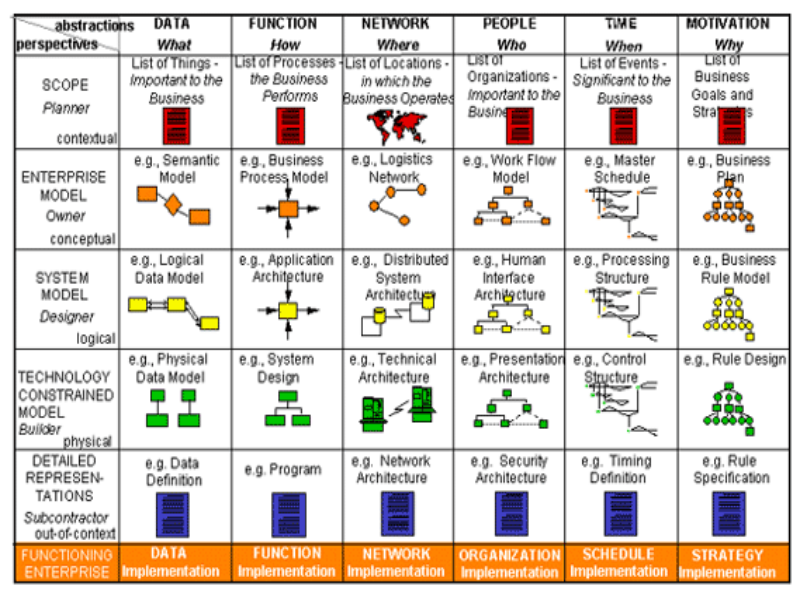

Gambar 2. Zachman Framework

(Pramana dan Yuningsih, 2013)

Urutan pada sisi kolom terdapat 6 jenis deskripsi yang meliputi (Syarif, 2015) : 
a. Kolom what (data), berfokus pada hubungan antar entitas dengan menguraikan relasi antara data yang satu dengan lainnya.

b. Kolom how (proses atau fungsi), berfokus pada penyataan fungsi atau input dan output dengan mendeskripsikan keseluruhan proses yang terjadi dalam organisasi, proses kegiatan pemenuhan kebutuhan stakeholder, dan proses input dan output yang terjadi pada organisasi.

c. Kolom where (jaringan), berfokus pada nodes dan links yang menjelaskan lokasi operasional dari organisasi, struktur bangunan dan lokasi hingga peta instalasi jaringan yang dimiliki oleh organisasi tersebut.

d. Kolom who (sumber daya manusia), berfokus pada peran dan tanggung jawab yang memdeskripsikan alokasi sumber daya manusia menurut struktur dan tanggung jawab dalam organisasi.

e. Kolom when (waktu), berfokus pada siklus waktu yang mendeskripsikan setiap waktu terjadinya proses dalam suatu organisasi yang memiliki relasi dalam membangun kriteria kinerja dan tingkat kualitatif untuk sumber daya organisasi.

f. Kolom why (motivasi), berfokus pada visi, misi, dan tujuan organisasi yang mendeskripsikan motivasi dan tujuan akhir organisasi berserta strategi dan metode pencapaian yang digunakan oleh organisasi.

Sedangkan urutan pada sisi baris terdapat 6 jenis deskripsi yang meliputi:

a. Sasaran dan ruang lingkup mendefinisikan model bisnis fungsional secara global dan berbagai persyaratan atau kebutuhan eksternal organisasi.

b. Model enterprise mendefinisikan setiap model bisnis, alokasi fungsi bisnis, proses eliminasi setiap fungsi yang overlap dan ambigu.

c. Model sistem mendefinisikan setiap model logikal, manajemen proyek, dan pendefinisian persyaratan dan kebutuhan.

d. Model teknologi mendefinisikan setiap model fisik, manajemen teknologi, dan pendefinisian solusi dan pengembangannya.

e. Representasi detail mendefinisikan konsep manajemen konfigurasi sistem dan implementasi pembangunan sistem.

f. Kinerja organisasi atau perusahaan mendefinisikan berbagai macam panduan bagi pengguna sehingga dapat menggunakan sistem, melakukan manajemen operassi, dan mengevaluasi sistem.

\section{E. Enterprise Architecture Planning (EAP)}

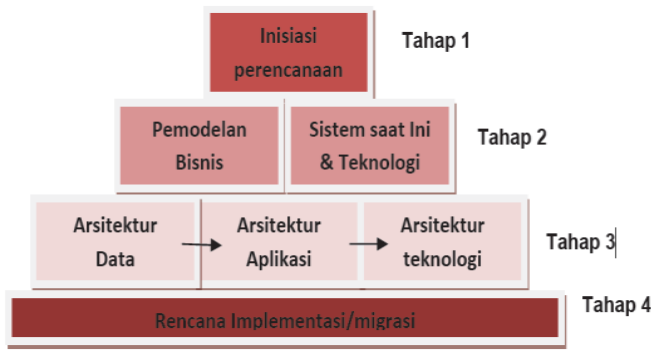

Gambar 3. Tahapan Enterprise Architecture Planning (Rosida, 2014).

Dalam pengembangan suatu struktur EAP terdapat 4 tahapan yaitu tahapan untuk memulai, tahapan untuk memahami kondisi saat ini, tahapan pendefinisian masa depan, dan tahapan untuk menyusun rencana dalam mencapai visi masa depan. Dibawah ini adalah gambar dari tahapan perencanaan arsitektur 
enterprise yaitu (Rosida, 2014). Pada gambar 3 enterprise architecture planning setiap tahapan memiliki penjelasan yang saling menghubungkan antara tahapan pertama, kedua, ketiga dan keempat yang dapat dijelaskan sebagai berikut:

\section{a. Tahap 1: Inisiasi Perencanaan}

Terdiri dari penentuan metodologi yang digunakan, siapa yang akan terlibat, dan tools apa yang akan digunakan. Hasilnya adalah rencana untuk EAP dan komitmen manajemen untuk melanjutkan ke enam tahap berikutnya.

b. Tahap 2: Pemahaman kondisi saat ini

Tahap ini terdiri dari dua bagian yaitu: Memodelkan bisnis, Tahapan ini mengompilasi dan membangun suatu basis pengetahuan mengenai bisnis dan informasi yang digunakan bisnis saat ini. Sistem saat ini dan teknologi, mendefinisikan sistem aplikasi dan platform teknologi yang ada untuk mendukung bisnis saat ini.

c. Tahap 3: Rencana Masa Depan

Pada tahap ini terdapat 3 bagian yaitu: Arsitektur Data, Mendefinisikan jenis data utama yang diperlukan bagi bisnis. Arsitektur Aplikasi, Mendefinisikan jenis-jenis aplikasi yang dibutuhkan untuk mengolah data dan mendukung fungsi bisnis. Arsitektur Teknologi, Mendefinisikan platform teknologi yang dibutuhkan untuk menghasilkan suatu lingkungan bagi aplikasi pengelola data dan pendukung fungsi bisnis.

d. Tahap 4: Strategi Pencapaian

Tahap rencana implementasi atau migrasi, mendefinisikan urutan untuk implementasi aplikasi, jadwal unutk implementasi, analisis biaya/manfaat dan mengusulkan jalur unutk migrasi dari kondisi saat ini ke kondisi yang diinginkan.

\section{HASIL DAN PEMBAHASAN}

\section{Inisialisasi Perencanaan}

Ruang lingkup yang digunakan untuk melakukan penelitian ini adalah seputar proses bisnis perusahaan yang berhubungan dengan penginputan data stok produk serta pengiriman barang ke tempat ritel. Adapun visi dan misi yang dimiliki oleh perusahaan sebagai berikut:

a. Menjadi supporting yang tidak menyerah untuk memuaskan anakanak perusahaan.

b. Memberikan dukungan yang professional dan terunggul sehingga anak-anak perusahaan dapat menggapai misinya.

c. Melakukan kontrol dan membuat keputusan strategis agar anak-anak perusahaan memiliki hidup yang berkualitas.

\section{Kondisi Bisnis Saat Ini}

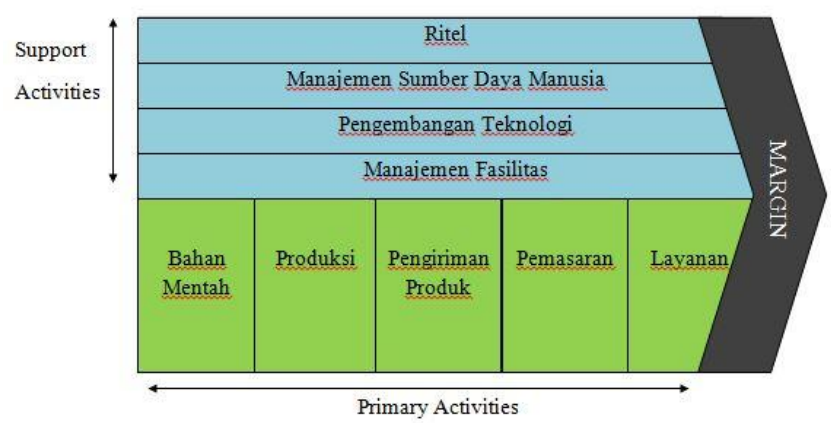

\section{Gambar 4. Value Chain}

Berdasarkan hasil dari pendefinisian aktivitas utama dan aktivitas pendukung menggunakan value chain, maka terdapat hasil sebagai berikut: 
Dari gambar 4. value chain maka dapat dijelaskan sebagai berikut:

a. Inbound Logistic, aktivitas perusahaan yang berhubungan dengan pengiriman bahan material yang didapat dari supplier.

b. Operations, aktivitas perusahaan dalam mengelola material atau bahan mentah di dalam pabrik yang disediakan oleh perusahaan.

c. Outbound Logistic, aktivitas perusahaan dalam proses pengiriman produk yang sudah dikelola ke masing-masing ritel.

d. Marketing and Sales, aktivitas yang dilakukan perusahaan dalam hal pemasaran produk yang dijual.

e. Service, merupakan layanan yang diberikan oleh perusahaan kepada client agar tetap membeli produk yang mereka pasarkan.

f. Firm Infrastructure, infrastruktur yang mendukung jalan nya proses bisnis didalam perusahaan.

g. Human Resource Management, aktivitas yang dilakukan oleh perusahaan untuk mengelola sumber daya manusia yang dimiliki oleh perusahaan.

h. Technology Development, teknologi pendukung yang digunakan oleh perusahaan baik berupa hardware maupun software yang membantu proses jalannya bisnis.

i. Procurement, merupakan peralatan yang digunakan oleh perusahaan untuk membantu proses jalannya bisnis.

Setelah mengetahui aktivitasaktivitas yang ada baik utama dan pendukung yang ada didalam perusahaan, selanjutnya adalah hasil dari analisis SWOT nya:

\section{Tabel 1. Hasil Analisis SWOT}

\begin{tabular}{|c|c|c|}
\hline Strength & Weakness & \\
\hline $\begin{array}{l}\text { a.Memiliki cabang } \\
\text { lebih dari satu yang } \\
\text { tersebar hampir di } \\
\text { seluruh Indonesia. } \\
\text { b.Memiliki lokasi yang } \\
\text { strategis. } \\
\text { c.Memiliki berbagai } \\
\text { jenis perhiasan yang } \\
\text { dijual kepada } \\
\text { pelanggan. }\end{array}$ & $\begin{array}{l}\text { a. Website yang dimiliki } \\
\text { oleh jewelry company } \\
\text { kurang berkembang. } \\
\text { b.Metode pengiriman } \\
\text { barang masih belum } \\
\text { terorganisir dengan baik. } \\
\text { c.Pencatatan pemesanan } \\
\text { produk oleh client masih } \\
\text { dilakukan secara } \\
\text { manual. }\end{array}$ & 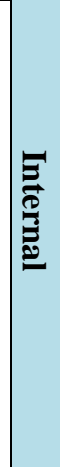 \\
\hline Opportunities & Threat & \\
\hline $\begin{array}{l}\text { a.jewelry } \\
\text { memiliki } \\
\text { yang menpapplier } \\
\text { bahan material } \\
\text { berkualitas. } \\
\text { b.Memiliki karyawan } \\
\text { yang handal dalam } \\
\text { menarik minat } \\
\text { pelanggan. } \\
\text { c.Terdapat teknologi } \\
\text { IT yang mendukung } \\
\text { proses bisnis jewelry } \\
\text { company. }\end{array}$ & $\begin{array}{l}\text { a.Banyak yang berjualan } \\
\text { perhiasan dengan nama- } \\
\text { nama terkenal yang } \\
\text { berasal dari luar datang } \\
\text { ke Indonesia. } \\
\text { b.Apabila tidak mengikuti } \\
\text { perkembangan teknologi } \\
\text { dapat memberikan } \\
\text { dampak yang buruk } \\
\text { terhadap kinerja } \\
\text { perusahaan. } \\
\text { c.Perlu melakukan inovasi } \\
\text { baru dalam menerapkan } \\
\text { metode penjualan agar } \\
\text { tetap menarik } \\
\text { pelanggan. }\end{array}$ & 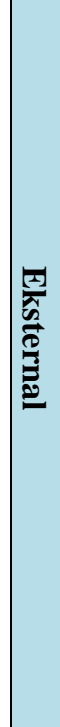 \\
\hline
\end{tabular}

3. Sistem dan Teknologi Saat ini

Sistem dan teknologi yang berjalan dalam proses bisnis saat ini adalah sebagai berikut:

a. Proses dimulai pada saat pimpinan perusahaan memesan bahan material untuk membuat perhiasan kepada supplier. Setelah kesepakatan dibuat antara pihak dari perusahaan dengan pihak supplier berunding mengenai harga yang ditentukan, kemudian supplier akan mengirim bahan 
material tersebut ke tempat pabrik pembuatan perhiasan. Pada tahap selanjutnya, bahan material tadi akan di proses ke dalam mesin yang ada di dalam pabrik, setelah melalui proses pemisahan antara batu perhiasan dengan batu yang tidak ada isinya, selanjutnya adalah tahap pembuatan perhiasan. Namun sebelum melalui tahap tersebut, penentuan design perhiasan akan di terapkan terlebih dahulu. Setelah adanya proses persetujuan design yang sudah ditentukan, selanjutnya akan melalui proses produksi perhiasan sesuai dengan design yang sudah ditetapkan. Dari hasil yang sudah jadi, maka perhiasan tersebut akan melalui tahap penentuan massa dan karat perhiasan.

Tabel 2. Kondisi Sistem dan Teknologi Perusahaan

\begin{tabular}{|l|l|l|l|l|}
\hline Divisi & $\begin{array}{l}\text { Penyimp } \\
\text { anan } \\
\text { Data }\end{array}$ & $\begin{array}{l}\text { Siste } \\
\text { m } \\
\text { Oper } \\
\text { asi }\end{array}$ & $\begin{array}{l}\text { Peran } \\
\text { gkat } \\
\text { Lunak }\end{array}$ & $\begin{array}{l}\text { Perang } \\
\text { kat } \\
\text { Pendu } \\
\text { kung }\end{array}$ \\
\hline $\begin{array}{l}\text { Keuan } \\
\text { gan }\end{array}$ & $\begin{array}{l}\text { HDD } \\
\text { internal } \\
\text { dan } \\
\text { eksternal }\end{array}$ & $\begin{array}{l}\text { Wind } \\
\text { ows 7 }\end{array}$ & $\begin{array}{l}\text { Micros } \\
\text { oft } \\
\text { Office }\end{array}$ & $\begin{array}{l}\text { Printer, } \\
\text { fax, } \\
\text { Wifi }\end{array}$ \\
\hline
\end{tabular}

Tahap selanjutnya adalah proses packaging perhiasan yang disesuaikan dengan ketersediaan inventori dari masing-masing ritel. apabila dari masing-masing ritel ada kekurangan atau barang yang kosong maka karyawan akan melakukan proses penentuan pengiriman barang. Kepada ritel tersebut.

b. Teknologi yang digunakan pada perusahaan saat ini masing berupa Microsoft Office untuk membuat laporan keuangan, email dan beberapa komputer dan laptop, printer, mesin fax, serta wifi untuk koneksi dengan internet.

\section{Analisis Hasil Kondisi Saat Ini}

Dari pembahasan diatas, mulai dari value chain serta kondisi sistem dan teknologi perusahaan saat ini, maka dapat diambil kesimpulan bahwa masih terdapat kelemahan. Maka, perlu dibuat suatu perencanaan tabel 3.:

\section{Tabel 3. Usulan Aplikasi}

\begin{tabular}{|c|c|c|}
\hline Proses & Aplikasi & Keterangan \\
\hline Pemasaran & $\begin{array}{c}\text { Company } \\
\text { Profile } \\
\text { Website }\end{array}$ & $\begin{array}{c}\text { Pengembangan } \\
\text { Baru }\end{array}$ \\
\hline $\begin{array}{c}\text { Pencatatan } \\
\text { produk }\end{array}$ & $\begin{array}{l}\text { Pencatatan } \\
\text { Stok Barang }\end{array}$ & $\begin{array}{c}\text { Pengembangan } \\
\text { Baru }\end{array}$ \\
\hline $\begin{array}{c}\text { Pemesanan } \\
\text { barang }\end{array}$ & $\begin{array}{c}\text { Pemesanan } \\
\text { Barang }\end{array}$ & $\begin{array}{c}\text { Pengembangan } \\
\text { Baru }\end{array}$ \\
\hline Penggajian & Penggajian & $\begin{array}{c}\text { Pengembangan } \\
\text { Baru }\end{array}$ \\
\hline $\begin{array}{c}\text { Pengolahan } \\
\text { absensi }\end{array}$ & $\begin{array}{l}\text { Sistem } \\
\text { Absensi }\end{array}$ & $\begin{array}{c}\text { Pengembangan } \\
\text { Baru }\end{array}$ \\
\hline $\begin{array}{c}\text { Pengontrolan } \\
\text { pengiriman }\end{array}$ & $\begin{array}{c}\text { Pengontrolan } \\
\text { Pengiriman }\end{array}$ & $\begin{array}{c}\text { Pengembangan } \\
\text { Baru }\end{array}$ \\
\hline
\end{tabular}

Pada Tabel 3. usulan aplikasi menunjukkan beberapa proses yang telah direncanakan dalam proses bisnis. Berikut penjelasannya:

a. Pemasaran, proses ini memiliki aktivitas untuk menawarkan dan menyebarkan informasi mengenai produk yang dijual oleh perusahaan.

b. Pencatatan produk, proses ini memiliki aktivitas untuk mencatat segala produk perhiasan serta membuat laporan mengenai ketesediaan pada masing-masing produk.

c. Pemesanan barang, proses ini merupakan aktivitas yang dilakukan oleh client dalam memesan produk kepada karyawan yang bekerja di tempat ritel.

d. Penggajian, proses ini dilakukan oleh pimpinan yang memberikan 
penggajian pada karyawan setiap bulannya.

e. Pengontrolan pengiriman, proses ini merupakan aktivitas yang dilakukan oleh karyawan untuk membuat segala penjadwalan pengiriman serta laporan penerimaan packaging yang dikirimkan kepada masing-masing ritel.

\section{Arsitektur Data}

Berikut adalah arsitektur data yang dibutuhkan pada setiap proses yang berhubungan dengan aplikasi yang diusulkan beserta prioritas aplikasi.

Tabel 4. Kebutuhan Data Setiap Aplikasi

\begin{tabular}{|c|c|}
\hline Aplikasi & $\begin{array}{c}\text { Kebutuhan } \\
\text { Data }\end{array}$ \\
\hline $\begin{array}{c}\text { Company Profile } \\
\text { Website }\end{array}$ & $\begin{array}{c}\text { Akun, informasi } \\
\text { umum } \\
\text { perusahaan, dan } \\
\text { contact us }\end{array}$ \\
\hline $\begin{array}{c}\text { Pencatatan Stok } \\
\text { Barang }\end{array}$ & $\begin{array}{c}\text { Akun, stok } \\
\text { barang masuk } \\
\text { dan keluar. }\end{array}$ \\
\hline Pemesanan Barang & $\begin{array}{c}\text { Akun, stok } \\
\text { barang yang } \\
\text { tersedia, } \\
\text { pemesanan } \\
\text { produk }\end{array}$ \\
\hline Penggajian & $\begin{array}{c}\text { Akun, informasi } \\
\text { karyawan, gaji }\end{array}$ \\
\hline Sistem Absensi & Sistem Absensi \\
\hline Pengontrolan & $\begin{array}{c}\text { Akun, } \\
\text { penjadwalan } \\
\text { pengiriman }\end{array}$ \\
\hline
\end{tabular}

Tabel 5. Rancangan Pengguna dan Prioritas

\begin{tabular}{|c|c|c|}
\hline Aplikasi & Pengguna & Prioritas \\
$\begin{array}{c}\text { Company } \\
\text { Profile } \\
\text { Website }\end{array}$ & Admin & Sedang \\
\hline $\begin{array}{c}\text { Pencatatan } \\
\text { Stok Barang }\end{array}$ & Karyawan & Tinggi \\
\hline $\begin{array}{c}\text { Pemesanan } \\
\text { Barang }\end{array}$ & Karyawan & Sedang \\
\hline $\begin{array}{c}\text { Penggajian } \\
\text { Pimpinan, } \\
\text { Karyawan }\end{array}$ & Sedang \\
\hline Absensi & Karyawan & Sedang \\
\hline $\begin{array}{c}\text { Pengontrolan } \\
\text { Pengiriman }\end{array}$ & Karyawan, & Tinggi \\
\hline
\end{tabular}

6. Arsitektur Aplikasi

Tabel 6. Rincian Aplikasi

\begin{tabular}{|c|c|}
\hline $\begin{array}{c}\text { Kandidat } \\
\text { Aplikasi }\end{array}$ & Deskripsi \\
\hline $\begin{array}{c}\text { Company } \\
\text { Profile } \\
\text { Website }\end{array}$ & $\begin{array}{c}\text { Digunakan untuk memasarkan } \\
\text { produk yang dijual oleh } \\
\text { perusahaan kepada masyarakat }\end{array}$ \\
\hline $\begin{array}{c}\text { Pencatatan } \\
\text { Stok Barang }\end{array}$ & $\begin{array}{c}\text { Aplikasi yang membantu } \\
\text { dalam menyimpan sejumlah } \\
\text { produk yang di produksi oleh } \\
\text { perusahaan. }\end{array}$ \\
\hline $\begin{array}{c}\text { Pemesanan } \\
\text { Barang }\end{array}$ & $\begin{array}{c}\text { Aplikasi yang digunakan untuk } \\
\text { menyimpan pemesanan yang } \\
\text { dimintai oleh client. }\end{array}$ \\
\hline Penggajian & $\begin{array}{c}\text { Aplikasi yang digunakan untuk } \\
\text { membantu proses penggajian } \\
\text { karyawan didalam perusahaan. }\end{array}$ \\
\hline Sistem & Aplikasi yang membantu \\
Absensi & $\begin{array}{c}\text { karyawan dalam proses absensi } \\
\text { didalam perusahaan. }\end{array}$ \\
\hline $\begin{array}{c}\text { Pengontrolan } \\
\text { Pengiriman } \\
\text { Barang }\end{array}$ & $\begin{array}{c}\text { Aplikasi yang digunakan untuk } \\
\text { membuat jadwal pengiriman ke } \\
\text { setiap masing-masing ritel. }\end{array}$ \\
\hline
\end{tabular}

Bagian ini menjelaskan mengenai aplikasi-aplikasi yang telah diusulkan kepada perusahaan ini. usulan aplikasi ini 
didasari atas pertimbangan dari blueprint arsitektur yang telah dibuat menggunakan Zachman Framework. Berikut rinciannya pada tabel 6. rincian aplikasi.

Dari hasil usulan aplikasi tersebut maka didapatkan portofolio aplikasi. Portofolio ini akan membantu pengurutan dalam implementasi ke perusahaan. Berikut adalah portofolionya.

Tabel 7. Portofolio Aplikasi

\begin{tabular}{|c|c|}
\hline Strategis & Berorientasi Tinggi \\
\hline $\begin{array}{l}\text { Aplikasi pencatatan } \\
\text { stok barang, } \\
\text { pemesanan barang, } \\
\text { sistem absensi }\end{array}$ & $\begin{array}{l}\text { Aplikasi pengontrolan } \\
\text { pengiriman barang }\end{array}$ \\
\hline Operasional Kunci & Pendukung \\
\hline $\begin{array}{c}\text { Aplikasi Penggajian } \\
\text { Karyawan }\end{array}$ & $\begin{array}{c}\text { Company Profile } \\
\text { website }\end{array}$ \\
\hline
\end{tabular}

\section{Arsitektur Teknologi}

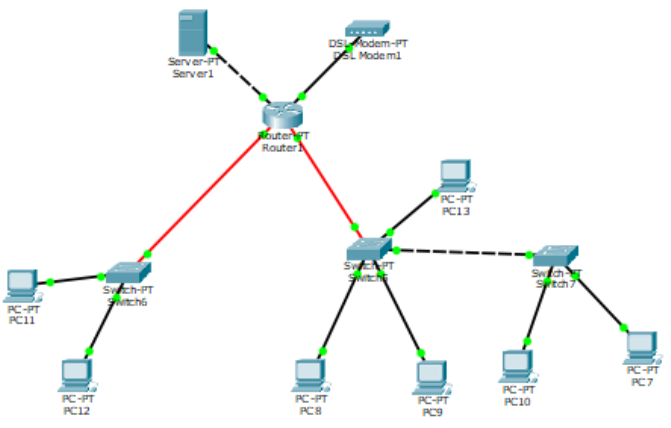

\section{Gambar 6. Peta Jaringan Yang Diusulkan}

Bagian ini akan menentukan bentuk jaringan seperti apa yang diusulkan untuk diterapkan di dalam perusahaan agar mendukung berjalannya aplikasi yang diusulkan sebelumnya. Pada topologi yang diusulkan memiliki jenis topologi star. Dimana apabila terjadi kerusakan pada salah satu komputer, maka tidak akan mempengaruhi komputer yang lain didalam perusahaan tersebut. berikut adalah bentuk topologi pada gambar 6. Peta Jaringan Yang Diusulkan.

Untuk infrastruktur yang diharapkan memiliki spesifikasi yang digunakan untuk mendukung jalannya aplikasi seperti pada tabel 8. Usulan Infrastruktur Teknologi.

\section{Tabel 8. Usulan Infrastruktur Teknologi}

\begin{tabular}{|c|c|c|c|}
\hline No & $\begin{array}{c}\text { Nama } \\
\text { Peralatan }\end{array}$ & Spesifikasi & $\begin{array}{c}\text { Jumla } \\
\text { h }\end{array}$ \\
\hline 1 & $\begin{array}{c}\text { Mikrotik } \\
\text { routerboard }\end{array}$ & RB 941 & 1 \\
\hline 2 & $\begin{array}{l}\text { Switch TP- } \\
\text { LINK }\end{array}$ & SF1024D & 1 \\
\hline 3 & Kabel jaringan & CAT 7 & $200 \mathrm{~m}$ \\
\hline \multirow{11}{*}{4} & Web server & & \multirow{11}{*}{1} \\
\hline & Processor & $\begin{array}{c}\text { Intel core I3 } 2.4 \\
\text { GHZ }\end{array}$ & \\
\hline & Motherboard & Q150 & \\
\hline & Memory & $4 \mathrm{~GB}$ & \\
\hline & Harddisk & 1TB GB & \\
\hline & LAN Card & Gigabyte & \\
\hline & Processor & $\begin{array}{l}\text { Intel core I3 } 2.4 \\
\text { GHZ }\end{array}$ & \\
\hline & Motherboard & Q150 & \\
\hline & Memory & $8 \mathrm{~GB}$ & \\
\hline & Harddisk & $1 \mathrm{~TB}$ & \\
\hline & LAN Card & Gigabyte & \\
\hline
\end{tabular}

8. Perencanaan Proyek dan Implementasinya

Bagian ini akan menjelaskan mengenai time schedule yang diperlukan untuk pelaksanaan persiapan pembangunan proyek beserta implementasinya. Pada perencanaan arsitektur yang ada. Terdapat empat tipe yang terdiri dari data, aplikasi, teknologi, dan proses bisnis. Setiap dari perencanaan arsitektur adanya dampak positif dan negative yang kemungkinan dapat terjadi di dalam perusahaan. Sedangkan untuk waktu pengerjaan pada masingmasing perencanaan arsitektur memiliki jangka waktu yang berbeda-beda sesuai dengan tingkat kesulitan pengerjaan pada masing-masing proses seperti yang 
ada pada tabel 9. Pertimbangan Blueprint Arsitektur.

Tabel 9. Pertimbangan Blueprint Arsitektur

\begin{tabular}{|c|c|c|c|}
\hline $\begin{array}{c}\text { Renca } \\
\text { na } \\
\text { arsitek } \\
\text { tur }\end{array}$ & $\begin{array}{c}\text { Dampak } \\
\text { Positif }\end{array}$ & $\begin{array}{c}\text { Dampak } \\
\text { Negatif }\end{array}$ & $\begin{array}{c}\text { Waktu } \\
\text { Pengerj } \\
\text { aan }\end{array}$ \\
\hline Data & $\begin{array}{l}\text { Menghubu } \\
\text { ngan data } \\
\text { dan } \\
\text { aplikasi } \\
\text { dari jarak } \\
\text { dekat } \\
\text { maupun } \\
\text { jarak jauh }\end{array}$ & $\begin{array}{l}\text { Memerluk } \\
\text { an biaya } \\
\text { yang } \\
\text { cukup } \\
\text { besar. }\end{array}$ & $\begin{array}{c}1-2 \\
\text { Bulan. }\end{array}$ \\
\hline $\begin{array}{l}\text { Aplikas } \\
\text { i }\end{array}$ & $\begin{array}{l}\text { Dalam } \\
\text { pelaksanaa } \\
\mathrm{n} \text { aktivitas } \\
\text { didalam } \\
\text { perusahaan } \\
\text { menjadi } \\
\text { lebih } \\
\text { mudah. }\end{array}$ & $\begin{array}{l}\text { Biaya } \\
\text { besar serta } \\
\text { waktu } \\
\text { yang } \\
\text { dibutuhka } \\
\text { n cukup } \\
\text { lama. }\end{array}$ & $\begin{array}{c}6-8 \\
\text { Bulan. }\end{array}$ \\
\hline $\begin{array}{c}\text { Teknol } \\
\text { ogi }\end{array}$ & $\begin{array}{l}\text { Dengan } \\
\text { adanya } \\
\text { sistem } \\
\text { yang } \\
\text { terhubung } \\
\text { dengan } \\
\text { teknologi } \\
\text { dapat } \\
\text { membantu } \\
\text { sistem } \\
\text { berjalan } \\
\text { dengan } \\
\text { baik }\end{array}$ & $\begin{array}{l}\text { Membutu } \\
\text { hkan } \\
\text { waktu } \\
\text { yang } \\
\text { cukup } \\
\text { lama serta } \\
\text { biaya } \\
\text { yang } \\
\text { besar } \\
\text { untuk } \\
\text { membang } \\
\text { un } \\
\text { jaringan } \\
\text { komputer. }\end{array}$ & $\begin{array}{c}3-4 \\
\text { Bulan. }\end{array}$ \\
\hline $\begin{array}{l}\text { Proses } \\
\text { Bisnis }\end{array}$ & $\begin{array}{l}\text { Perencanaa } \\
\mathrm{n} \text { berjalan } \\
\text { dengan } \\
\text { baik, } \\
\text { sehingg } \\
\text { meminimal } \\
\text { kan resiko } \\
\text { terhadap } \\
\text { sistem. }\end{array}$ & & $\begin{array}{r}4-6 \\
\text { bulan. }\end{array}$ \\
\hline
\end{tabular}

\section{KESIMPULAN}

Berdasarkan hasil analisis menggunakan Zachman Framework terdapat kesimpulan sebagai berikut: a. Agar proses bisnis dalam perusahaan dapat terus meningkat hendaknya perusahaan menerapkan SI/TI secara lebih maksimal sehingga strategi bisnis yang dijalankan dapat terus semakin berkembang sejalan dengan visi dan misi dari perusahaan.

b. Dari hasil perencanaan enterprise architecture menggunakan Zachman Framework, terdapat enam aplikasi yang disarankan kepada perusahaan, yaitu company profile website, pencatatan stok barang, pemesanan barang, penggajian, sistem absensi dan pengontrolan pengiriman.

\section{DAFTAR PUSTAKA}

Bakar, N., Harihodin., \& Kama, N. (2016). Assesment of enterprise architecture implementation capability and priority in public sector agency. Procedia Computer Science.

Hizbullah, I., Nugroho, E., \& Santosa, P. (2015). Model perencanaan strategis SI/TI perguruan tinggi menggunakan framework togaf (studi kasus stkip kie raha). Seminar Nasional Ilmu Komputer, 189-193.

Irmanyani, W. (2015). Enterprise architecture planning (EAP) menggunakan togaf ADM pada dinas cipta karya, tata ruang dan kebersihan kabupaten kubu raya. Jurnal Katulistiwa Informatika, 3, 94-105.

Kristanto, T. (2016). Enterprise Architecture Planning Untuk Pengelolaan Manajemen Aset dengan Zachman Framework. Jurnal Ilmiah Tecknologi Sistem Informasi, 2, 2.

Pramana, D., \& Yuningsih, L. (2013). Implementasi Zachman Framework pada Sistem Reservasi Online Studi kasus Hotel XYZ. STMIK AMIKOM. 
Rosida (2014). Perencanaan Architectur Enterprise Menggunakan Zachman

Framework (Studi kasus: PT PLN(Persero) Pusat Pemeliharaan Ketenagalistrikan). Jurnal Informasi.

Saputra, D. (2015). Perancangan enterprise architecture zachman framework untuk jasa layanan pasang baru dan tambah daya listrik pada perusahaan jasa listrik swasta. Jurnal Katulistiwa Informatika, 3, 11-24.

Slameto, A., Utami, E., \& Pangera, A. (2013). Penerapan zachman framework dalam merancang sistem pelaporan kerusakan komputer. STMIK AMIKOM

Subagio, R. (2012). Pemodelan arsitektur enterprise STMIK CIC Cirebon menggunakan enterprise architecture planning. Jurnal Sistem Informasi, 7, 173-185.

Syarif, A (2015). Desain Arsitektur Enterprise Sistem Informasi Manajemen Kampus Menggunakan Zachman Framework (Studi Kasus Universitas Atma Jaya Makassar). Makassar. 